\title{
Spectrum of haemodynamic responses to atrial pacing in coronary artery disease ${ }^{\mathrm{I}}$
}

\author{
P. A. N. Chandraratna, P. M. Shah ${ }^{2}$, D. H. Kramer, R. J. Davis, and B. F. Schreiner \\ From the Cardiology Unit, Department of Medicine, University of Rochester Medical Center, \\ New York 14642 , U.S.A.
}

\begin{abstract}
Atrial tachy-pacing was performed in 34 patients who were divided into 3 groups as follows. Group $I: 4$ patients with obscure chest pain syndromes and normal coronary arteries and haemodynamics; Group 2: 25 patients with significant coronary artery disease and angina pectoris; Group 3: 5 patients with coronary artery disease, left ventricular aneurysm, and left ventricular dysfunction. Pacing produced a reduction in the left ventricular stroke work index and the left ventricular end-diastolic pressure in Group I patients, while the cardiac index and the left ventricular minute work index showed no significant change. Group 2 patients showed a variety of responses. Nine patients had a 'normal' response to atrial pacing, namely a fall in left ventricular stroke work index and left ventricular end-diastolic pressure. Of these, 5 had experienced angina during pacing and 4 did not; the other 16 had abnormal responses. When considered as a group, there was a significant decrease in the left ventricular stroke work index and an increase in the left ventricular minute work index, while the left ventricular end-diastolic pressure and cardiac index did not change significantly. Group 3 patients demonstrated a significant fall in the left ventricular end-diastolic pressure and a rise in the cardiac index and the left ventricular minute work index, while the left ventricular stroke work index was unchanged. A reduction in the end-diastolic pressure without a fall in stroke work index and with an increase in the minute work index indicate improved myocardial performance in this group of patients. It is concluded that there is a wide spectrum of responses to atrial pacing ranging from no change in left ventricular function in some patients to gross dysfunction in others. Those with compromised left ventricular function exhibit improved performance.
\end{abstract}

Sowton and associates were the first to show that atrial tachy-pacing produced angina pectoris in patients with coronary artery disease. Using this as a stress test they showed that chest pain consistently occurred at a particular tension-time index in a given patient, and that during angina stroke volume and left ventricular stroke work decreased while pulmonary artery mean pressure and the pulmonary wedge pressure increased (Sowton et al., 1967). Atrial pacing is now widely used in the evaluation of left ventricular function in coronary artery disease (Parker et al., 1969; Leighton et al., 1969; Dwyer, 1970; Linhart, I97I). It has been a useful method Received 29 March 1973.

1 This work was supported in part by a MIRU contract and grants from the National Heart and Lung Institute, Bethesda, Maryland, U.S.A.

2 This work was done during Dr. Shah's tenure of an American Heart Association Teaching Scholar Award. of studying the effects of drugs in angina pectoris (Frick et al., 1968) and more recently has been employed to assess the results of coronary artery surgery (Ross et al., 1972).

Parker and associates using left ventricular catheterization found that when heart rate was increased by atrial pacing the normal response was a fall in stroke work index and left ventricular end-diastolic pressure (Parker et al., 1969). In contrast when angina occurred, left ventricular dysfunction was suggested because of a rise in end-diastolic pressure and a decrease in stroke work index. The rise in end-diastolic pressure, moreover, was most conspicuous in the first few beats after brief interruption of pacing. More recently, Linhart observed that similar changes suggesting left ventricular dysfunction might occur in patients with ischaemic heart disease who do not develop angina during atrial 
pacing and that in some patients abnormal function appeared before the onset of angina (Linhart, 1971). Both groups of authors chose to construct ventricular function curves relating left ventricular enddiastolic pressure to stroke work index with pacing intervention. These relations do not represent the classic Frank-Starling function curves nor do they duplicate the concepts of Sarnoff and Berglund who derived a given function curve only in the presence of a constant inotropic state (Sarnoff and Berglund, 1954). The Bowditch effect whereby an increased heart rate results in an augmented inotropic state has been largely discounted in these pacing studies.

The purposes of the present study are (I) to show that there is a wide spectrum of responses to atrial pacing in patients with symptomatic coronary artery disease; (2) to indicate that patients with angina may have a normal response or a conspicuously abnormal response, whereas those with ventricular aneurysm and left ventricular failure may show an improvement in cardiac performance during atrial pacing. It is further emphasized that pacing function curves in fact represent points on different function curves as classically expressed.

\section{Methods}

Thirty-four symptomatic patients with suspected coronary artery disease were studied. The patients were divided into three groups. Group $I$ consisted of 4 men (age range 19 to 60 years) with atypical chest pain syndromes who had normal coronary arteries and no detectable cardiac abnormality. Group 2 comprised 25 patients, 20 men and 5 women (age range 33 to 68 years) who had disabling angina pectoris (Class III New York Heart Association Classification) and coronary artery disease documented by selective coronary angiography with the exception of Case 17 who had chest pain with electrocardiographic abnormalities of ischaemia during pacing, but had insignificant lesions in her coronary angiogram. Group 3 was composed of 5 men (age 30 to 63 years) who had left ventricular aneurysm and evidence of cardiac decompensation.

Right and left heart catheterizations were performed in the postabsorptive state under pentobarbitone sedation. A flow-directed Swan Ganz catheter was passed into the pulmonary artery via the right antecubital vein. A bipolar pacing catheter was placed in the coronary sinus, or in the right atrium. A cannula was placed in a brachial artery. Left heart catheterization was performed using either the Brockenbrough transseptal technique or the Seldinger retrograde technique from a femoral artery. Lead II and lead V5 of the electrocardiogram were monitored. The pulmonary artery, pulmonary artery wedge or left atrial pressure, left ventricular, and brachial artery pressures were recorded on a Brush recorder through Statham P23dB strain gauge transducers. The zero reference point used was $5 \mathrm{~cm}$ below the sternal angle. Mean pressures were determined by electronic integration. The left ventricular end-diastolic pressure measurement was facilitated by using a high gain and paper speed of 50 or $100 \mathrm{~mm} / \mathrm{sec}$. The end-diastolic pressure was measured at the point where the downslope of the ' $a$ ' wave was interrupted by the upstroke of left ventricular pressure rise. With rapid heart rates when this transition could not be precisely discerned, the pressure was read at $0.04 \mathrm{sec}$ after onset of QRS at both control and paced rates. All pressures were measured over two respiratory cycles and averaged. The 'pace-off LV enddiastolic pressure' was obtained after transient interruption of pacing. The left ventricular end-diastolic pressure from ten consecutive beats after cessation of pacing was averaged. Cardiac output determinations were made by the dye dilution technique using indocyanine green injected into the pulmonary artery and sampled from the brachial artery through a Gilford densitometer. ${ }^{1}$ The left ventricular stroke work index in $\mathrm{g} \mathrm{m} /$ beat and minute work were calculated using standard formulae.

Control pressures were measured and cardiac output was determined in duplicate. Atrial pacing was then begun with increments in heart rate of to to 20 beats/ minute at a time with continuous pressure recordings. Measurements of cardiac output were made in duplicate after pacing for 5 minutes at each heart rate. When chest pain or discomfort similar to that experienced by the patient during exertion occurred with pacing, no further increase in heart rate was attempted. In other patients the heart rate was progressively increased, usually to a maximum of $150 /$ minute. In some patients this heart rate could not be achieved because of impaired AV conduction (Cases 25, 31, 32, 33).

After haemodynamic studies, left ventricular angiocardiography was performed in each patient. Selective coronary arteriography was carried out on a subsequent day by the Judkins technique.

\section{Results}

\section{Haemodynamic data}

The haemodynamic data of individual patients are presented in Table $\mathbf{I}$. The mean values for each group are shown in Table 2. Eighteen patients in Group 2 and I patient in Group 3 developed angina during pacing. The control heart rates before pacing were similar in Groups I and 2, but were somewhat higher in Group 3 patients. The cardiac index during the control period and pacing was not significantly different in Groups I and 2, but was significantly higher during pacing in Group 3 patients. The left ventricular end-diastolic pressure decreased significantly during atrial pacing in Groups I and 3, but there was no significant change in Group 2. A significant fall in the left ventricular stroke work index was observed during pacing in Groups I and 2, but no change occurred in Group 3. The left ventricular minute work index increased significantly during atrial pacing in Groups 2 and 3, but remained unchanged in Group $I$.

1 Model I03 IR. 
The relation of end-diastolic pressure to stroke work index for patients in Groups I, 2, and 3, was examined. The mean value and the standard error of the mean during the control period and during pacing are shown in Fig. I. All 4 patients in Group I showed normal responses to atrial pacing, i.e. a fall in end-diastolic pressure and a concomitant decrease in stroke work index.

Seven patients in Group 2 did not experience angina during pacing. Of these, 4 showed a fall in stroke work index as well as end-diastolic pressure, in 2 there was a fall in stroke work index with a rise in end-diastolic pressure, and the remaining patient showed a fall in stroke work index with no change in end-diastolic pressure. Five of the 18 patients in Group 2 who developed angina during pacing had a fall in both stroke work index and end-diastolic pressure; the other 13 had increased end-diastolic pressure associated with a fall in stroke work index. When considered as a group; they demonstrated a significant fall in stroke work index during pacing with no change in end-diastolic pressure (Fig. I). Four of the 5 patients in Group 3 showed a fall in end-diastolic pressure and a rise in stroke work index during pacing. Fig. I shows that these patients when considered as a group demonstrate a fall in

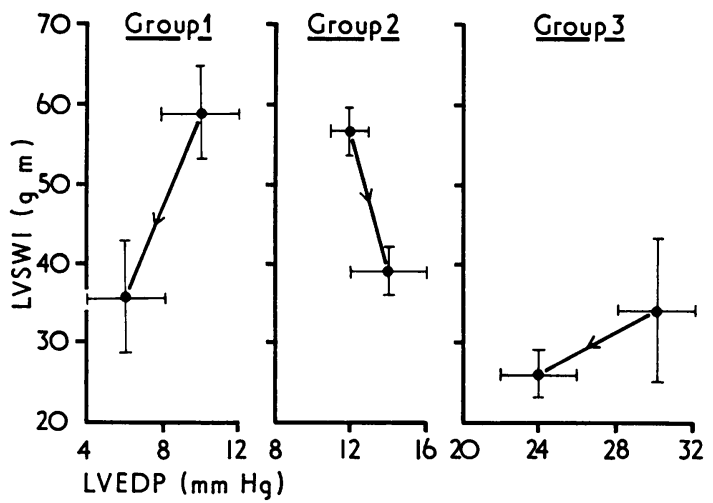

FIG. I The relation between left ventricular stroke work index (LVSWI $g \mathrm{~m} /$ beat) and left ventricular end-diastolic pressure (LVEDP $\mathrm{mmHg}$ ) is illustrated. The mean value and the standard error of the mean for each group, during the control period and during pacing, are given. The control and pacing values are joined and the arrows point toward the pacing values. Group I patients show a significant reduction in the stroke work index and end-diastolic pressure during pacing $(P<0.05)$. There is a reduction in stroke work index in Group 2 patients with pacing $(P<0.001)$, while the end-diastolic pressure shows no significant change. The end-diastolic pressure in Group 3 patients decreased with pacing $(P<0.01)$, while the stroke work index did not change significantly.

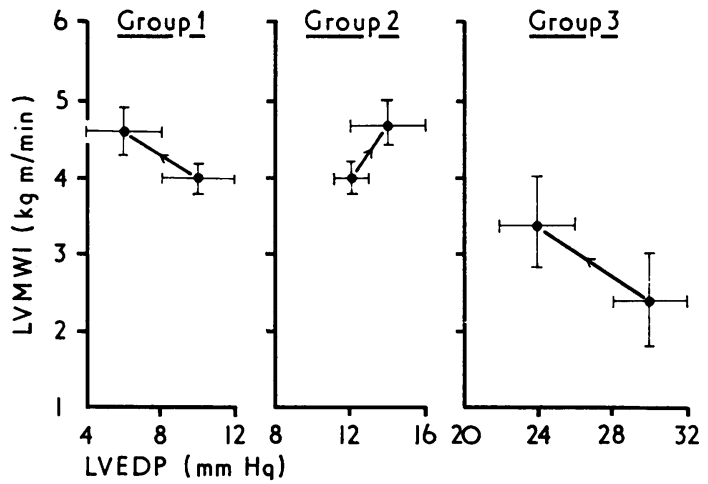

FIG. 2 This shows the relation between left ventricular minute work index ( $L V M W I \mathrm{~kg} \mathrm{~m} / \mathrm{min}$ ) and the left ventricular end-diastolic pressure (LVEDP $\mathrm{mm}$ $\mathrm{Hg}$ ). The mean value and the standard error of the mean for each group, during the control period and during pacing, are given. The control and pacing values are joined and the arrows point toward the pacing values. Group I patients show a reduction in the end-diastolic pressure $(P<0.05)$, but no significant change in the $L V$ minute work index, during pacing. There is an increase in the latter in Group 2 patients with pacing $(P<0.01)$ while the end-diastolic pressure is unchanged. The end-diastolic pressure in Group 3 patients decreased with pacing $(P<0.01)$ and this was associated with an increase in the minute work index $(P<0.01)$.

end-diastolic pressure during pacing with no significant change in stroke work index. The relation between minute work index and end-diastolic pressure was also examined (Fig. 2). Again, a spectrum of responses was seen. When considered together, Group I patients demonstrated a significant fall in end-diastolic pressure, but no significant change in the minute work index. There was a rise in the minute work index during atrial pacing in Group 2, but no change was observed in the end-diastolic pressure. The increase in minute work index was largely due to increase in systemic arterial pressure, especially in those experiencing angina. Group 3 patients, however, had a significant rise in minute work index and a fall in end-diastolic pressure when the heart rate was increased. Pacing was interrupted and end-diastolic pressure during the subsequent ro beats measured in 20 patients. In 4 patients (Case 5, II, I6, and 22) the end-diastolic pressure rose from a normal value during pacing to a distinctly abnormal one with pace interruption, thus unmasking an abnormality in left ventricular function.

Direct left atrial pressures during the control period and during atrial pacing were measured in I7 patients. In 9 patients the end-diastolic pressure 
TABLE I Haemodynamic data of patients studied

\begin{tabular}{|c|c|c|c|c|c|c|c|c|c|}
\hline $\begin{array}{l}\text { Case } \\
\text { No. }\end{array}$ & State & $\begin{array}{l}\text { Heart } \\
\text { rate/min }\end{array}$ & $\begin{array}{l}\text { LV end- } \\
\text { diastolic } \\
\text { pressure } \\
(\mathrm{mmHg})\end{array}$ & $\begin{array}{l}\text { Pace off } \\
\text { LV end- } \\
\text { diastolic } \\
\text { pressure } \\
(m m H g)\end{array}$ & $\begin{array}{l}\text { Left atrial } \\
\text { mean } \\
(m m H g)\end{array}$ & $\begin{array}{l}\text { Brachial } \\
\text { artery } \\
\text { mean } \\
(\mathrm{mmHg})\end{array}$ & $\begin{array}{l}\text { Cardiac } \\
\text { index } \\
\text { (l./min per } \\
\left.m^{2}\right)\end{array}$ & $\begin{array}{l}\text { LV stroke } \\
\text { work index } \\
(\mathrm{g} \text { m/beat })\end{array}$ & $\begin{array}{l}L V \text { minute } \\
\text { work index } \\
(\mathrm{kg} \mathrm{m} / \mathrm{min})\end{array}$ \\
\hline \multicolumn{10}{|c|}{ Group I } \\
\hline \multirow[t]{2}{*}{ I } & Control & 65 & IO & - & - & 97 & $2 \cdot 80$ & $66 \cdot 2$ & $4 \cdot 30$ \\
\hline & Pace & 150 & 8 & 13 & 9 & 95 & $2 \cdot 74$ & $26 \cdot 5$ & $3 \cdot 97$ \\
\hline \multirow[t]{2}{*}{2} & Control & 60 & 15 & - & - & 105 & $3 \cdot 10$ & $69 \cdot 7$ & $4 \cdot 20$ \\
\hline & Pace & 100 & 10 & 12 & - & 105 & $4 \cdot 20$ & 55 & 5.50 \\
\hline \multirow[t]{2}{*}{3} & Control & 75 & 8 & - & 6 & 90 & $3 \cdot 04$ & 47 & 3.50 \\
\hline & Pace & 145 & 5 & - & - & 100 & $3 \cdot 30$ & $3 I$ & 4.50 \\
\hline \multirow[t]{2}{*}{4} & Control & 80 & 7 & - & 4 & 100 & $3 \cdot 10$ & 52 & $4 \cdot 16$ \\
\hline & Pace & I5O & I & - & 3 & 105 & 2.98 & 30 & 4.50 \\
\hline \multicolumn{10}{|c|}{ Group 2} \\
\hline \multirow[t]{2}{*}{5} & Control & 75 & 6 & - & 7 & 100 & $3 \cdot 10$ & 55 & 3.90 \\
\hline & Pace & 150 & 8 & 20 & II & 105 & 2.90 & 27 & 4.05 \\
\hline \multirow[t]{2}{*}{6} & Control & 100 & 12 & - & Io & 110 & 4.08 & 57 & $5 \cdot 70$ \\
\hline & Pace & 150 & IO & - & 14 & 120 & 4.05 & 42 & $6 \cdot 30$ \\
\hline \multirow[t]{2}{*}{7} & Control & 85 & 7 & - & 4 & 105 & $3 \cdot 16$ & 53 & 4.50 \\
\hline & Pace & 150 & 5 & 6 & - & 100 & 3.04 & 28 & $4 \cdot 20$ \\
\hline \multirow[t]{2}{*}{8} & Control & 86 & I3 & - & 8 & 100 & 3.83 & 56 & $4 \cdot 80$ \\
\hline & Pace & 105 & 13 & 14 & - & I 10 & 3.96 & 53 & $5 \cdot 60$ \\
\hline \multirow[t]{2}{*}{9} & Control & 78 & 13 & - & 9 & 85 & $1 \cdot 65$ & 21 & $1 \cdot 64$ \\
\hline & Pace & 125 & 18 & - & 10 & 88 & $I \cdot 8 I$ & 17 & $2 \cdot 12$ \\
\hline \multirow[t]{2}{*}{ IO } & Control & 75 & 13 & - & Io & 125 & $2 \cdot 60$ & $52 \cdot 2$ & 3.92 \\
\hline & Pace & 120 & 7 & - & 10 & 125 & $2 \cdot 41$ & $37 \cdot 3$ & $4 \cdot 52$ \\
\hline \multirow[t]{2}{*}{ II } & Control & 78 & 13 & - & 8 & 82 & $3 \cdot 26$ & $42 \cdot 7$ & $3 \cdot 32$ \\
\hline & Pace* & I50 & 6 & 20 & 8 & 90 & $3 \cdot 46$ & $27 \cdot 8$ & $4 \cdot 15$ \\
\hline \multirow[t]{2}{*}{12} & Control & 80 & 8 & - & 7 & 130 & $3 \cdot 35$ & 75 & $6 \cdot 00$ \\
\hline & Pace* & 155 & 20 & 30 & 13 & 140 & 3.56 & 40.5 & $6 \cdot 30$ \\
\hline 13 & Control & 60 & 6 & - & 3 & 75 & $2 \cdot 46$ & $59 \cdot 7$ & $3 \cdot 48$ \\
\hline & Pace* & 135 & 8 & - & 一 & 80 & 2.54 & 19.8 & $2 \cdot 70$ \\
\hline 14 & Control & 85 & I3 & - & - & 90 & $2 \cdot 58$ & $34 \cdot 2$ & $2 \cdot 90$ \\
\hline & Pace* & 100 & 27 & 25 & - & II5 & $2 \cdot 66$ & $34 \cdot 3$ & $3 \cdot 42$ \\
\hline 15 & Control & 70 & Io & - & 7 & 120 & $2 \cdot 91$ & $64 \cdot 5$ & 4.51 \\
\hline & Pace* & 105 & 6 & - & - & 120 & $2 \cdot 97$ & $44 \cdot 8$ & $4 \cdot 70$ \\
\hline 16 & Control & 65 & 8 & - & - & I 10 & 2.92 & $66 \cdot 9$ & $4 \cdot 50$ \\
\hline & Pace* & 130 & II & 18 & - & 105 & $2 \cdot 84$ & $30 \cdot 1$ & 3.90 \\
\hline 17 & Control & 82 & 8 & - & 6 & 110 & $3 \cdot 30$ & 56 & $4 \cdot 70$ \\
\hline & Pace* & 143 & 5 & - & 3 & 115 & $2 \cdot 86$ & 32 & 4.56 \\
\hline 18 & Control & 60 & 10 & - & 5 & 80 & $2 \cdot 43$ & $4 I \cdot 6$ & $2 \cdot 50$ \\
\hline & Pace* & 90 & 25 & - & 30 & 85 & $2 \cdot 00$ & 19.5 & $1 \cdot 75$ \\
\hline 19 & Control & 54 & 12 & - & 7 & 97 & $2 \cdot 40$ & $56 \cdot 1$ & 3.00 \\
\hline & Pace* & 136 & 7 & 13 & II & 102 & $2 \cdot 88$ & $26 \cdot 6$ & $3 \cdot 60$ \\
\hline 20 & Control & 75 & 9 & - & 6 & 110 & $2 \cdot 86$ & 56.6 & $4 \cdot 20$ \\
\hline & Pace* & 145 & 23 & 28 & - & 130 & 3.47 & $37 \cdot 7$ & 5.45 \\
\hline 21 & Control & 65 & 9 & - & 7 & 92 & $2 \cdot 73$ & $50 \cdot 5$ & $3 \cdot 30$ \\
\hline & Pace* & 107 & II & - & 8 & II7 & 3.09 & $45 \cdot 5$ & 4.90 \\
\hline 22 & Control & 63 & 10 & - & 6 & 142 & $2 \cdot 60$ & $79 \cdot 7$ & $5 \cdot 00$ \\
\hline & Pace* & 110 & II & 15 & 7 & 195 & $2 \cdot 88$ & $69 \cdot 5$ & $7 \cdot 60$ \\
\hline 23 & Control & 73 & 6 & - & 3 & 95 & $2 \cdot 70$ & $47 \cdot 5$ & 3.48 \\
\hline & Pace* & 130 & 5 & Io & 7 & 100 & $2 \cdot 50$ & $26 \cdot 5$ & $3 \cdot 40$ \\
\hline 24 & Control & 75 & 16 & - & 8 & 125 & $2 \cdot 76$ & 58 & $4 \cdot 35$ \\
\hline & Pace* & 135 & 16 & 25 & I7 & 150 & $3 \cdot 00$ & $42 \cdot 7$ & 5.75 \\
\hline 25 & Control & 58 & 16 & - & II & 145 & 2.50 & $74 \cdot 7$ & $4 \cdot 39$ \\
\hline & Pace & 97 & 13 & 23 & - & 160 & $3 \cdot 40$ & $73 \cdot 1$ & 6.90 \\
\hline 26 & Control & 69 & 25 & - & - & 99 & $3 \cdot 38$ & $52 \cdot 5$ & $3 \cdot 60$ \\
\hline & Pace* & 130 & 34 & - & - & 112 & 3.07 & $26 \cdot 5$ & 3.44 \\
\hline 27 & Control & 59 & 15 & - & 12 & 132 & $2 \cdot 89$ & 83 & $4 \cdot 80$ \\
\hline & Pace* & 120 & 6 & Io & - & 147 & $3 \cdot 82$ & 65 & $7 \cdot 80$ \\
\hline 28 & Control & 70 & 15 & - & IO & 95 & $2 \cdot 71$ & $48 \cdot 3$ & $3 \cdot 38$ \\
\hline & Pace* & 107 & 25 & I7 & I5 & 125 & $3 \cdot 05$ & $45 \cdot 4$ & 4.85 \\
\hline 29 & Control & 65 & 21 & - & 19 & 125 & $3 \cdot 18$ & $73 \cdot 5$ & $4 \cdot 80$ \\
\hline & Pace* & 97 & 32 & 32 & 40 & 170 & $3 \cdot 17$ & 65 & $6 \cdot 30$ \\
\hline
\end{tabular}


TABLE I continued

\begin{tabular}{|c|c|c|c|c|c|c|c|c|c|}
\hline $\begin{array}{l}\text { Case } \\
\text { No. }\end{array}$ & State & $\begin{array}{l}\text { Heart } \\
\text { rate/min }\end{array}$ & $\begin{array}{l}\text { LV end- } \\
\text { diastolic } \\
\text { pressure } \\
(\mathrm{mmHg})\end{array}$ & $\begin{array}{l}\text { Pace off } \\
\text { LV end- } \\
\text { diastolic } \\
\text { pressure } \\
(\mathrm{mmHg})\end{array}$ & $\begin{array}{l}\text { Left atrial } \\
\text { mean } \\
(\mathrm{mmHg})\end{array}$ & $\begin{array}{l}\text { Brachial } \\
\text { artery } \\
\text { mean } \\
(m m H g)\end{array}$ & $\begin{array}{l}\text { Cardiac } \\
\text { index } \\
\text { (l./min per } \\
\left.m^{2}\right)\end{array}$ & $\begin{array}{l}L V \text { stroke } \\
\text { work index } \\
(\mathrm{g} \text { m/beat })\end{array}$ & $\begin{array}{l}L V \text { minute } \\
\text { work index } \\
(\mathrm{kg} \mathrm{m} / \mathrm{min})\end{array}$ \\
\hline \multicolumn{10}{|c|}{ Group 3} \\
\hline \multirow[t]{2}{*}{30} & Control & 120 & 37 & - & 37 & 105 & $2 \cdot I I$ & $18 \cdot 2$ & $2 \cdot 18$ \\
\hline & Pace & 150 & 28 & 38 & 28 & 105 & $2 \cdot 23$ & $21 \cdot 5$ & 3.20 \\
\hline \multirow[t]{2}{*}{$3 I$} & Control & 75 & 25 & - & - & 82 & $1 \cdot 88$ & 17 & $1 \cdot 28$ \\
\hline & Pace & IIO & 18 & - & - & 80 & $2 \cdot 24$ & 20 & $2 \cdot 20$ \\
\hline \multirow[t]{2}{*}{32} & Control & 95 & 33 & - & - & 90 & 3.00 & 25.9 & $2 \cdot 46$ \\
\hline & Pace & 125 & 30 & - & 30 & 100 & 3.65 & 30 & 3.75 \\
\hline \multirow[t]{2}{*}{33} & Control & 85 & 28 & - & 23 & 80 & $1 \cdot 80$ & $17 \cdot 1$ & $1 \cdot 45$ \\
\hline & Pace & 120 & 25 & - & - & 90 & $2 \cdot 10$ & 21 & 2.50 \\
\hline \multirow[t]{2}{*}{34} & Control & 68 & 26 & - & 13 & 135 & $2 \cdot 6 \mathrm{I}$ & $66 \cdot 3$ & 4.50 \\
\hline & Pace* & 145 & 18 & 22 & I5 & 150 & $2 \cdot 70$ & $35 \cdot 6$ & $5 \cdot 15$ \\
\hline
\end{tabular}

* The asterisks indicate patients who developed angina during pacing, and the values given are those observed during paceinduced angina.

TABLE 2 Summary of haemodynamic data. The mean values \pm standard error are given

\begin{tabular}{|c|c|c|c|c|c|c|c|}
\hline & $\begin{array}{l}\text { Heart } \\
\text { rate/min }\end{array}$ & $\begin{array}{l}L V \text { end-dias- } \\
\text { tolic pressure } \\
(\mathrm{mmHg})\end{array}$ & $\begin{array}{l}\text { Left atrial } \\
\text { mean }(m m H g)\end{array}$ & $\begin{array}{l}\text { Brachial } \\
\text { artery mean } \\
(\mathrm{mmHg})\end{array}$ & $\begin{array}{l}\text { Cardiac index } \\
(\text { l./min per } \\
\left.m^{2}\right)\end{array}$ & $\begin{array}{l}L V \text { stroke } \\
\text { work index } \\
(\mathrm{g} \text { m/beat })\end{array}$ & $\begin{array}{l}\text { LV minute } \\
\text { work index } \\
(\mathrm{kg} \mathrm{m} / \mathrm{min})\end{array}$ \\
\hline $\begin{array}{l}\text { Group I } \\
\text { Control } \\
\text { SE } \\
\text { Pace } \\
\text { SE }\end{array}$ & $\begin{array}{r}70 \\
136\end{array}$ & $\begin{array}{l}10 \\
\pm 2 \\
6 \\
\pm 2 \\
P<0.05\end{array}$ & $\begin{array}{l}5 \cdot 0 \\
6\end{array}$ & $\begin{array}{r}98 \\
\pm 3 \\
\text { IOI } \\
\pm 3 \\
N S\end{array}$ & $\begin{array}{r}3.0 \\
\pm 0.1 \\
3.3 \\
\pm 0.3 \\
\text { NS }\end{array}$ & $\begin{array}{l}58.7 \\
\pm 6 \\
35.6 \\
\pm 7 \\
P<0.05\end{array}$ & $\begin{array}{r}4.0 \\
\pm 0.2 \\
4.6 \\
\pm 0.3 \\
\text { NS }\end{array}$ \\
\hline $\begin{array}{l}\text { Group } 2 \\
\quad \text { Control } \\
\text { SE } \\
\text { Pace } \\
\text { SE }\end{array}$ & $\begin{array}{r}72 \\
124\end{array}$ & $\begin{array}{r}12 \\
\pm 1 \\
14 \\
\pm 2 \\
N S\end{array}$ & $\begin{array}{r}8 \\
14\end{array}$ & $\begin{array}{c}107 \\
\pm 4 \\
120 \\
\pm 5 \\
P<0.001\end{array}$ & $\begin{array}{r}2.9 \\
\pm 0.1 \\
3.0 \\
\pm 0.1 \\
\text { NS }\end{array}$ & $\begin{array}{l}56.6 \\
\pm 3 \\
39 \\
\pm 3 \\
P<0.001\end{array}$ & $\begin{array}{r}4.0 \\
\pm 0.2 \\
4.7 \\
\pm 0.3 \\
P<0.01\end{array}$ \\
\hline $\begin{array}{l}\text { Group } 3 \\
\text { Control } \\
\text { SE } \\
\text { Pace } \\
\text { SE }\end{array}$ & $\begin{array}{r}89 \\
130\end{array}$ & $\begin{array}{l}30 \\
\pm 2 \\
24 \\
\pm 2 \\
P<0.01\end{array}$ & $\begin{array}{l}27 \\
24\end{array}$ & $\begin{array}{r}98 \\
\pm 10 \\
84 \\
\pm 24 \\
\mathrm{NS}\end{array}$ & $\begin{aligned} 2.3 \\
\pm 0.2 \\
2.6 \\
\pm 0.3 \\
P<0.05\end{aligned}$ & $\begin{array}{l}28.9 \\
\pm 9 \\
25.9 \\
\pm 3 \\
\text { NS }\end{array}$ & $\begin{array}{r}2.4 \\
\pm 0.6 \\
3.4 \\
\pm 0.6 \\
P<0.01\end{array}$ \\
\hline
\end{tabular}

Note: Statistical method was standard paired ' $t$ ' test. 
decreased during atrial pacing and it was unchanged in one patient. In 8 of these the left atrial mean pressure either increased (6) or remained the same (2) and in the 2 other patients there was a concomitant decrease in left atrial mean. This decrepancy in the trends of the end-diastolic and mean pressures during atrial pacing is due to spurious rise in the left atrial mean resulting from fusion of the ' $a$ ' and ' $v$ ' waves (Leighton et al., 1969; Khaja and Parker, 1971). In the 7 patients in whom the end-diastolic pressure increased during pacing there was a corresponding rise in the left atrial mean in each case.

Unusual responses were observed in 2 patients in Group 2 (Fig. 3). One patient (Case 14) developed angina when the heart rate was increased from 60 to 90 beats/minute. The mean LA pressure rose from $5 \mathrm{mmHg}$ to $30 \mathrm{mmHg}$ with a ' $\mathrm{V}$ ' wave of 40 $\mathrm{mmHg}$. Another patient (Case 29) experienced an-

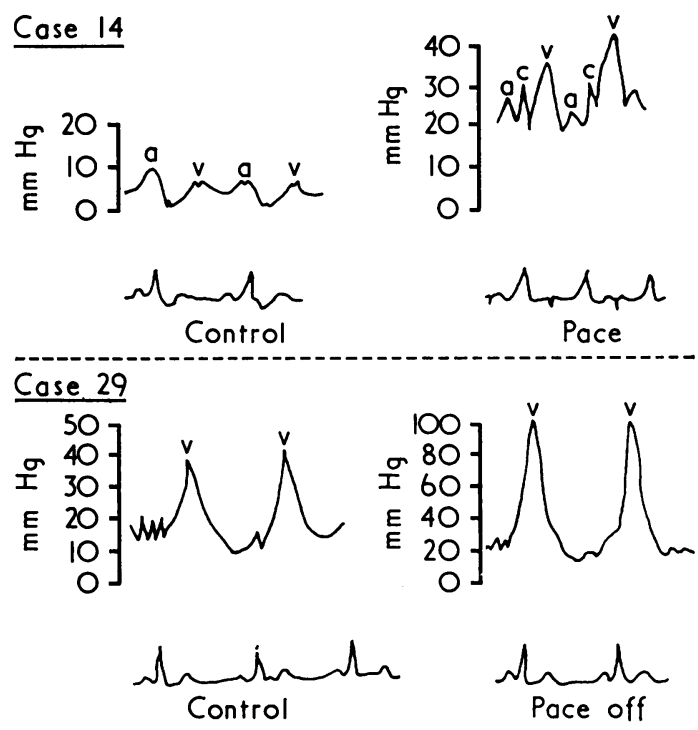

FIG. 3 The pressure tracings of two patients who showed unusual responses to pacing are illustrated. The upper panel shows the direct left atrial pressure trace of Case 14 during the control period (on the left) and during pace-induced angina (on the right). Note the tall ' $V$ ' wave in the tracing on the right, with a sharp $Y$ descent suggestive of mitral incompetence. Case 29 (lower panel) had mitral incompetence at rest as shown by a tall ' $V$ ' wave in the pulmonary artery wedge pressure tracing (trace on the left). During pace-induced angina the ' $V$ ' wave became more pronounced. The tall ' $V$ ' wave persisted for several minutes when pacing was stopped (trace on the right), suggesting a sharp accentuation of mitral incompetence. gina on increasing the heart rate from 65 to 97 a minute, with a rise in the ' $V$ ' wave of the pulmonary wedge pressure from $40 \mathrm{mmHg}$ to $100 \mathrm{mmHg}$ which persisted for several minutes when pacing was discontinued (Fig. 3).

\section{Discussion}

Several investigations have supported the original observations of Bowditch (1871) that an increase in frequency of cardiac stimulation augments ventricular performance (Woodworth, 1902). Mitchell and associates studied the effects of heart rate on ventricular performance in the areflexic dog heart, in which the stroke volume and the mean aortic pressures were maintained constant (Mitchell, Wallace, and Skinner, 1963). Their results suggested that there was an increased velocity and force of contraction when the heart rate was increased. Sonnenblick and associates investigated the influence of heart rate on the dynamics of the intact human ventricle (Sonnenblick, Morrow, and Williams, I966). The maximum rate of force development increased when the rate was raised, but there was little effect on the peak contractile force, suggesting that in man there is a 'velocity staircase' rather than a 'force staircase'. A more recent report indicates that the maximal intrinsic velocity of contractile elements $\left(V_{\max }\right)$ is increased significantly during atrial pacing suggesting an augmented contractile state (Bowyer et al., 1971).

The use of atrial pacing as a stress test for evaluation of patients with coronary artery disease has been shown to be of practical value. Some investigators have attempted to construct Sarnoff function curves relating left ventricular end-diastolic pressure to stroke work based on data obtained at different heart rates. Though pacing 'function curves' are shown to be different in the normal and in the diseased ventricle, one has reservations about constructing curves following interventions that are constantly changing myocardial contractility. A pacing 'function curve' is probably derived from joining points on different ventricular function curves.

The results of the present study show that though 'normal' patients respond uniformly to pacing with a fall in left ventricular end-diastolic pressure and stroke work index (normal response), those with coronary artery disease exhibit a wide spectrum of responses. In patients with stable angina pectoris without evidence of left ventricular dysfunction at rest, end-diastolic pressure fails to decrease as stroke work index falls at heart rates sufficient to develop angina. Indeed, transient interruption of pacing may unmask conspicuously raised left ventricular enddiastolic pressure (abnormal response). However, 26 
per cent of patients in Group 2 in the present study had decreased end-diastolic pressure and stroke work index after pacing despite the development of angina. On the other hand, of the 7 patients in Group 2 in whom pacing stress was insufficient to provoke angina, the haemodynamic response was 'normal' in 4 and abnormal in 3.This wide variation in haemodynamic response to pacing could not be correlated with the location or number of occlusive lesions in the coronary arterial tree. These results are not significantly different from individual patient data previously published (Linhart, 197I). Because of the significant increase of false positive and false negative results, pacing stress may not be reliably used as a diagnostic intervention in this group of patients.

Furthermore, patients having clinical evidence of congestive failure associated with coronary artery disease manifested a significant improvement in left ventricular function after pacing at more rapid heart rates. Four of 5 patients in this group showed a significant fall in end-diastolic pressure associated with an increase in stroke work index. This haemodynamic improvement may be due to the positive inotropic effect of tachycardia (Bowditch effect) on nonischaemic areas of the ventricle.

The haemodynamic responses to pacing may be further influenced by the development of mitral regurgitation as was seen in two patients in Group 2. Case 14 probably developed papillary muscle dysfunction and mitral regurgitation when stressed to angina as indicated by a sharp rise in the left atrial mean pressure from 5 to $30 \mathrm{mmHg}$. Similarly in Case 29 the pronounced increase of the ' $V$ ' wave in the left atrial pressure from 40 to $100 \mathrm{mmHg}$ reflects sharp accentuation of mitral regurgitation with the onset of pace-induced angina. Lesser degrees of mitral regurgitation in other patients may have gone undetected and could alter the relation between left ventricular stroke work index and left ventricular end-diastolic pressure.

Abnormal rise in end-diastolic pressure in the majority of patients paced to angina may reflect either decreased compliance from ischaemia or left ventricular dysfunction. The latter hypothesis is supported by angiographic observations on left ventricular wall motion made in our laboratory (Davis et al., 1972). Areas of akinetic and dyskinetic motion were observed after pace-induced angina in several patients. These findings support similar observations made by Dwyer (1970).

In conclusion, though a pacing stress is a useful intervention to study patients with stable angina pectoris, it may be unreliable in at least one-fourth of patients. A normal response to pacing stress cannot be equated with an absence of myocardial ischaemia from coronary artery disease since exercise treadmill test may be strongly positive even at low work loads. Patients with ischaemic heart disease show a wide spectrum of responses to atrial pacing. Left ventricular function may either be 'normal' with a drop in left ventricular end-diastolic pressure along with stroke work index, or may be grossly 'abnormal' with a rise in end-diastolic pressure despite a fall in stroke work index. Evaluation of left ventricular function may be further complicated by the development of mitral regurgitation from ischaemic dysfunction of papillary muscle. Finally, patients with ischaemic heart disease having clinical left ventricular failure associated with ventricular aneurysm may show significant improvement in ventricular performance as evidenced by decreased end-diastolic pressure with increase in stroke work index.

\section{References}

Bowditch, H. P. (187I). Uber die Eigenthumlichkeiten der Reizbarkeit, welche die Muskelfasern des Herzens zeigen. Berichte über die Verhandlungen der Königlich Sachsischen Gesellschaft der Wissenschaften zur Leipzig, 23, 652.

Bowyer, A. F., Allen, R. L., Schmidt, P. E., and Johns, V. J., Jr. (197I). Contractile element velocity during pacemaker tachycardia in man (abstract). Circulation, 44, Suppl. 2, 44.

Davis, R. J., Shah, P. M., Schreiner, B. F., Lipchik, E. O., and Kramer, D. H. (1972). Effects of pace induced angina on left ventricular wall motion (abstract). Circulation, 46, Suppl. 2, I44.

Dwyer, E. M. (1970). Left ventricular pressure-volume alterations and regional disorders of contraction during myocardial ischemia induced by atrial pacing. Circulation, 42, IIII.

Frick, M. H., Balcon, R., Cross, D., and Sowton, E. (1968). Hemodynamic effects of nitroglycerin in patients with angina pectoris studied by an atrial pacing method. Circulation, 37, 160.

Khaja, F., and Parker, J. O. (1971). Dissociation of left atrial pressure and left ventricular end-diastolic pressure during pacing induced tachycardia (abstract). Circulation, 44, Suppl. 2, 186.

Leighton, R. F., Zaron, S. J., Robinson, J. L., and Weissler, A. M. (1969). Effects of atrial pacing on left ventricular performance in patients with heart disease. Circulation, 40, 615.

Linhart, J. W. (197I). Myocardial function in coronary artery disease determined by atrial pacing. Circulation, 44, 203.

Mitchell, J. H., Wallace, A. G., and Skinner, N. S., Jr. (I963). Intrinsic effects of heart rate on left ventricular performance. American fournal of Physiology, 205, 4I.

Parker, J. O., Ledwich, J. R., West, R. O., and Case, R. B. (I969). Reversible cardiac failure during angina pectoris. Circulation, 39, 745.

Ross, D., Sutton, R., Dow, J., Gonzalez-Lavin, L., Hendrix, G., Jefferson, K., McDonald, L., Petch, M., Smithen, C., and Sowton, E. (1972). Venous graft surgery in treatment of coronary heart disease. British Medical fourwal, 2, 644 .

Sarnoff, S. J., and Berglund, E. (1954). Starling's law of the heart studied by means of simultaneous right and left ventricular function curves in the dog. Circulation, 9, 706. 
Sonnenblick, E. H., Morrow, A. G., and Williams, J. F., Jr. (1966). Effects of heart rate on the dynamics of force development in the intact human ventricle. Circulation, 33, 945 .

Sowton, G. E., Balcon, R., Cross, D., and Frick, M. H. (1967). Measurement of the angina threshold using atrial pacing. Cardiovascular Research, 1, 301.
Woodworth, R. S. (1902). Maximal contraction, staircasecontraction, refractory period, and compensatory pause, of the heart. American fournal of Physiology, 8, 213.

Requests for reprints to Dr. P. M. Shah, Cardiology Unit, Strong Memorial Hospital, 260 Crittenden Blvd., Rochester, New York I4642, U.S.A. 